O20 "DO PATIENTS WITH END-STAGE CHRONIC OBSTRUCTIVE PULMONARY DISEASE (COPD) ON MAXIMAL PHARMACOLOGICAL THERAPY WITH SPECIALIST RESPIRATORY CARE BENEFIT FROM PHARMACY TECHNICIAN LED MEDICATION REVIEW?"

Lisa Wall-Hayes, Louise Seager, Joanne Bartlett; John Taylor Hospice CIC, Birmingham, UK

\subsection{6/bmjspcare-2013-000591.20}

Introduction John Taylor Hospice runs a 9 week Fatigue, Anxiety \& Breathlessness (F. A. B.) programme for patients with end-stage COPD. All patients recruited to the programme were on maximal pharmacological therapy ${ }^{1}$ with regular input from both community and hospital specialist respiratory teams.

Aim and Objectives To ascertain if Pharmacy Technician led medication reviews would be a valuable addition to the programme.

Method Of the 11 patients recruited to the programme 6 were randomly selected for a domiciliary medication review by the Pharmacy Technician. Issues identified by the review were dealt with either at time of review or if necessary escalated to the appropriate professional for follow up. Interventions were categorised and recorded. Evaluation forms were completed by those receiving a review and a questionnaire was completed by those who had not.

Results 6 medication reviews were completed, 4 of which were in a domiciliary setting, whilst 2 took place at the hospice.

30 interventions were identified of which 13 were dealt with at the time of review, the remaining 17 were escalated.

Main categories of intervention were: Adherence/counselling and prescription issues.

Patient evaluation results: $100 \%$ of patients stated that the medication review was helpful, $100 \%$ also stated they now felt more confident managing their medication.

Patient feedback questionnaire results: $100 \%$ of patients who did not receive a medication review stated they would have found it useful.

Drug cost savings demonstrated: approximately $£ 560^{2}$ over 6 months.

Conclusion Patients with end-stage COPD on maximal pharmacological therapy with regular respiratory team involvement, still benefit from a Pharmacy Technician led medication review.

\section{ADVANCE CARE PLANNING - DEVELOPMENT OF A GROUP INTERVENTION FOR PEOPLE WITH NEWLY DIAGNOSED DEMENTIA AND THEIR FAMILIES}

Emily Madsen, Lorna Grey, Gillian Horne; Rowcroft Hospice, Torquay, England

\subsection{6/bmjspcare-2013-000591.21}

Background Rowcroft Hospice's strategic aim is 'taking care further'. This includes providing greater access to services and end of life care for people with non-cancer diagnoses. Working with Devon Partnership NHS Trust an intervention was developed to offer people post diagnosis with dementia, and their families/ carers in South Devon. The 'Planning Ahead' session is delivered as part of a 'Memory Matters' course.

Aim

- 4 weekly 2 hour sessions for those recently diagnosed with dementia and carers.

- Informal introduction to advance care planning - focus on changing ability to communicate and make decisions in the future.
- Provision of information about the legal framework and support tools.

- Promote choice - place of care, preferences, hopes and wishes, nature of medical intervention etc.

- Provide a supportive and safe group to explore these issues.

Approach An informal psycho-education group. The use of group discussion enables individuals to talk about personal experiences/concerns. This facilitates the sharing of information and literature specific to planning ahead. We used mixed media including: video clips, hand-outs, power point, local and national booklets.

Outcomes Initial evaluation by participants:

- Improved understanding about decision making in the event of changes in communication/capacity.

- These conversations are difficult to have/or start in families without support.

- Peer support/normalising effect of the group has been helpful.

Observations of facilitator:

- Shared opportunity to start difficult conversations.

- Carers empowered to consider their own preferences and wishes - the universal relevance of planning ahead for all.

- Individuals with dementia who attend need support to participate and encouragement to be involved.

- Carers/family members can dominate.

Application Advance Care Planning is a cornerstone of Specialist Palliative Care. Developing bespoke ways to meet the varying needs of different patient groups and their families is essential.

\section{HOSPICE-BASED MULTI-DISCIPLINARY CLINIC FOR END- STAGE RENAL FAILURE IMPROVES QUALITY OF CARE AND REDUCES HOSPITAL ADMISSION}

${ }^{1}$ Nicola Wilderspin, ${ }^{1}$ Marian Turner, ${ }^{2}$ Martin Ferring, ${ }^{2}$ Jenny Garside, ${ }^{3}$ Felix Blaine, ${ }^{3}$ Debbie Westwood; 'St Richard's Hospice, Worcester, UK, ${ }^{2}$ Worcestershire Acute Hospitals NHS Trust, ${ }^{3}$ South Worcestershire Clinical Commissioning Group

\subsection{6/bmjspcare-2013-000591.22}

Background/context Patients opting for conservative management of end-stage renal failure in South Worcestershire frequently died in hospital and struggled to attend acute hospital outpatient appointments.

Aims To improve quality of life through a new hospice-based model of care for conservative management of end-stage renal failure, and provide opportunities for advanced care planning and increased choice in end of life care.

Approach Patients and carers attend a flexible afternoon day hospice 'clinic' which begins with lunch and offers assessments with:

1. An acute hospital nephrologist to proactively manage renal complications such as anaemia and fluid balance.

2. A palliative care $\mathrm{CNS} /$ consultant for symptom control, carer assessment and advanced care planning.

Complementary therapies and informal chaplaincy support are also provided. Details of advance care plans are communicated to primary and secondary care, and inclusion on GP end of life care registers recommended. 